\title{
A concepção anisiana de educação: notas sobre a Educação Física
}

\section{RESUMO}

Este trabalho discute o pensamento de Anísio Teixeira sobre a Educação e o lugar, o papel indicado para a Educação Física em sua proposta de Educação Integral e da Educação do corpo no Centro Educacional Carneiro Ribeiro, inaugurado nos anos 1950, em Salvador/BA. Partimos da premissa que o projeto anisisano de educação teve um papel importante para a produção e legitimidade da Educação Física, como disciplina escolar, concorrendo com as perspectivas hegemônicas das disciplinas ditas propedêuticas. Trata-se de uma pesquisa documental em que foi analisado o discurso proferido por Anísio Teixeira na inauguração da Escola Parque e sua proposta educacional. Constatamos representações progressistas na proposta de Educação Física Escolar presente no projeto anisiano de educação.

PALAVRAS-CHAVE: Educação física; Educação integral; Anísio teixeira

\section{Roberto Gondim Pires}

Doutor em Educação

Universidade Estadual do Sudoeste da

Bahia, Departamento de Saúde I, Jequié,

Brasil

gondim.robeto@gmail.com

○https://orcid.org/0000-0002-5608-1343

\section{João Danilo Batista Oliveira}

Doutor em Educação

Universidade do Estado da Bahia,

Departamento de Educação I, Salvador,

Brasil

jdoliveira@uneb.br

https://orcid.org/0000-0002-4408-2744

Marcia Morel

Doutora em Educação

Universidade Estadual de Santa Cruz, Departamento de Ciências da Saúde, Ilhéus,

Brasil

mmorel@uesc.br

https://orcid.org/0000-0003-0746-4409 


\title{
The anisian conception of education: notes on Physical Education
}

\begin{abstract}
This paper discusses the thought of Anísio Teixeira about Education and place, the role indicated for Physical Education in his proposal for Integral Education and Education of the body at Centro Educacional Carneiro Ribeiro, inaugurated in the 1950s, in Salvador/BA. We start from the premise that the Anisisan education project played an important role in the production and legitimacy of Physical Education as a school subject, concurring with the hegemonic perspectives of the so-called propaedeutic disciplines. This is a documentary research in which the speech given by Anísio Teixeira at the inauguration of Escola Parque and its educational proposal was analyzed. We found progressive representations in the proposal of Physical Education in School present in the Anisian education project.
\end{abstract}

KEYWORDS: Physical education; Integral education; Anísio teixeira

\section{La concepción anisiana de educación: notas sobre Educación Física}

\section{RESUMEN}

En este artículo se analiza el pensamiento de Anísio Teixeira sobre Educación y lugar, papel señalado para la Educación Física en su propuesta de Educación Integral y Educación del cuerpo en el Centro Educacional Carneiro Ribeiro, inaugurado en la década de 1950, en Salvador/BA. Partimos de la premisa de que el proyecto educativo anisisano jugó un papel importante en la producción y legitimidad de la Educación Física como asignatura escolar, coincidiendo con las perspectivas hegemónicas de las denominadas disciplinas propedéuticas. Se trata de una investigación documental en la que se analizó el discurso pronunciado por Anísio Teixeira en la inauguración de la Escola Parque y su propuesta educativa. Encontramos representaciones progresistas en la propuesta de Educación Física en la Escuela presente en el proyecto educativo anisiano.

PALABRAS-CLAVE: Educación física; Educación integral; Anísio teixeira 


\section{INTRODUÇÃO}

Anísio Teixeira e outros educadores nacionais realizaram diversas contribuições para a área da Educação Física e muitos estudos sobre eles, igualmente, foram elaborados. Lembremo-nos que, durante muito tempo, a Educação Física no Brasil nutria-se quase que exclusivamente dos estudos de Fernando de Azevedo (1894-1968) e de Inezil Penna Marinho (1915-1987), estudiosos pioneiros da história da Educação Física e do Esporte no País (MELO, 1999).

O cenário de influências internacionais sofridas pela área da Educação Física, entre o final do século XIX e início do século XX, indicava a perspectiva da prática da atividade física, sob o pensamento hegemonicamente atrelado à função de forjar um homem disciplinado e obediente, apontando para uma perspectiva de desenvolvimento e progresso. Nesse contexto, o Parecer de Rui Barbosa (1883) estabelece um marco, sobretudo nos primórdios do período republicano e início do século XX, na defesa da implementação efetiva da Educação Física em nosso País.

Neste estudo, abordamos aspectos do pensamento e obra de Anísio Teixeira e as contribuições, lacunas e/ou contradições vividas pela Educação Física como área de conhecimento, ou mesmo como disciplina escolar, entre os anos 30 e 50 do século XX, período em que ficam marcadas iniciativas para a consolidação desta como disciplina escolar e para formação profissional na área.

Esse alvorecer da Educação Física nacional, com foco na prática e estreita relação com a instituição militar (HORTA, 1994), mesmo que inserido e imbuído de um espírito modernista de outros movimentos, como o Manifesto dos Pioneiros da Educação Nova (1932), contrastava com o pensamento deste movimento e, em especial, com o pensamento anisiano que vislumbrava a formação de homens livres, em vez de homens dóceis, que pensassem com clareza e tivessem uma atitude de inquietação diante dos fatos, com participação ativa na sociedade democrática (NUNES, 2009; 2010).

O pensamento educacional moderno, no seio das transformações históricas e sociais que dão origem ao capitalismo industrial, resguardadas as diferenças que o compõe, consagrou relativa importância à escolarização e à educação corporal e, aos poucos, foi definindo um lugar para a Educação Física na e com a escola (VAGO, 2012). Por influências de atores diversos (intelectuais, médicos, juristas, militares, professores) e instituições (médica, militar, estatal), reconhecendo as formações e os olhares distintos para a sociedade, trouxe nessa esteira a necessidade de escolarização do seu povo e de uma instituição para educar. Desse modo, as primeiras décadas do século XX foram marcadas por diversas reformas do ensino, em diferentes estados brasileiros.

O sistema educacional brasileiro era visto como um espaço que demandava intervenção para se adequar às necessidades de desenvolvimento da sociedade brasileira. As Reformas de Carneiro Leão (1922-1926), Fernando de Azevedo (1927-1930) e de Anísio Teixeira (1931-1935) tiveram 
correspondências normativas e graduais na política educacional da época e eram vistas como estratégicas para a mudança. $\mathrm{Na}$ verdade, todas as reformas citadas foram partícipes dessa reorganização da educação brasileira, a partir do Distrito Federal. Anísio lutava nesse contexto (luta ainda atual) contra a dualidade de um sistema educacional que distribuía as oportunidades educacionais de forma desigual. A escola, para Anísio, tinha um caráter universal (MOREL, 2016).

Nesse sentido, nos parece oportuno refletir sobre as contribuições que esse pensamento pode revelar para a Educação Física, ao introduzir no currículo do seu projeto de educação pública as artes do fazer (industrialismo) e as experiências de educação do corpo pelo esporte, teatro, dança e outras experiências corporais. Nesse aspecto, era claro que Anísio estava lutando contra a escola intelectualista de seu tempo e contra uma escola sem significados, esvaziada de experiências e sem vida (NUNES, 2000).

Em sua pesquisa, Morel (2016, p. 13) aponta que Anísio Teixeira idealizava a escola "como um lugar de desafios e prazer de viver aquele tempo e espaço educacional. Anísio, mesmo não sendo um sportsmen da sua época, pois, não sabia nadar, dançar, praticar esportes tinha verdadeira admiração pelas artes corporais e sua expressividade". Notabilizava-se pela defesa de uma escola pública popular que não reproduzisse a dicotomia entre trabalho intelectual e o trabalho manual. Sua premissa se sustentava na defesa da qualidade da educação prestada, na função social da escola como importante elemento de correção de desigualdades, de eliminação de privilégios e hierarquias sociais (NUNES, 2010).

Ao olharmos de um modo geral para a obra de Anísio Teixeira, em particular para a reforma educacional proposta por ele na Bahia, quando de sua gestão como Secretário de Educação e Saúde, buscamos capturar ideias e tecer notas sobre a Educação Física no seu projeto. Em especial, na implantação do Centro Educacional Carneiro Ribeiro em Salvador/BA (1950), como expressão da educação pública e da escola popular que ele defendia, constituído de Escola-Classe e Escola Parque.

Teria sido proposital, segundo testemunho de Guido Ivan de Carvalho no prefácio do livro de Eboli (1969), a construção de uma escola pública com as características do Centro nos bairros populares que concentram a maior densidade de população negra no mundo fora da África. Cabe-nos situar a implantação de Centros Populares de Educação na Bahia e/ou em Salvador, desse período, marcadas não só por uma sociedade com diferenças de classe, mas também com movimentos segregacionistas e discriminatórios, com inúmeros desdobramentos em estratificações sociais. Havia as relações de classe social: ricos e pobres; e aquelas relacionadas com as questões raciais: brancos ricos e pretos pobres.

Assim, sinalizamos a importância que as concepções do projeto anisiano tiveram na Educação, de um modo geral, e por extensão na Educação Física. Contudo, apontamos que, no que concerne à 
Educação Física, existem poucas análises e, assim, justificamos a relevância deste estudo. Este esforço, talvez, possa lançar luz sobre as perspectivas educacionais que ainda apresentam zonas de sombras, sobretudo na perspectiva da disciplina Educação Física em um projeto de educação popular, de integração entre 'saber fazer' e 'saber sobre o fazer', da lógica da integralidade humana, da educação em tempo integral, assim como, no campo da formação de professores de Educação Física.

\section{ASPECTOS HISTÓRICOS E CONSTATAÇÕES DISSONANTES ENTRE O PENSAMENTO DE ANÍSIO TEIXEIRA E A CONSTITUIÇÃO DA EDUCAÇÃO FÍSICA NACIONAL}

Pelo menos, dois fatos intrigam ou mesmo revelam a distância existente entre o projeto anisiano na defesa da sua Escola progressiva, sustentada na Escola Nova, e a constituição da Educação Física no Brasil e na Bahia. Pontuamos, como um primeiro fato, a produção e o delineamento apresentados no Manifesto dos Pioneiros da Educação Nova, que coincidem, do ponto de vista temporal, com iniciativas mais robustas de constituição do campo da Educação Física no Brasil, em um movimento em que podemos indicar que o pensamento anisiano nem influenciou com suas bases teórico-metodológicas, nem foi influenciado pelas concepções iniciais da Educação Física no Brasil.

A renovação a serviço da educação brasileira observada no período foi cunhada, em parte, pelo movimento escolanovista e seus protagonistas. Aqui consideramos como protagonistas os vários intelectuais e educadores conhecidos como renovadores e que faziam parte desse movimento. Afinados por esse ideal, estavam distantes de ser um grupo com posições idênticas; ainda assim, possuíam convergências de ideias, entre elas, a de um sistema de educação pública nacional e a revisão da organização tradicional da escola.

Nesse caso, era preciso mudar, ter uma escola diferente, uma nova mentalidade, transformar a antiga escola em uma escola nova. Entretanto, a Educação Física e outras disciplinas, consideradas relevantes na educação do corpo no escopo da concepção anisiana de educação, encontravam-se menosprezadas e em segundo plano no currículo. Podemos dizer que muitas das discussões em torno da Educação Física foram debatidas na Associação Brasileira de Educação (ABE), mais precisamente na Secção de Educação Physica e Higiene (SEPH).

Eram vários os interesses em torno de um projeto para a Educação Física nacional e a ABE era um lugar de circulação de diversos integrantes da política nacional e da sociedade civil, portanto, um campo de disputas na construção pedagógica para a Educação Física. Em referência à SEPH, Linhales (2009, p. 76) afirma que: 
[...] a diferenciação entre higiene e educação física se processa pela ampliação do debate pedagógico e político relativo à disciplina escolar Educação Física, que envolvia de modo especial uma disputa sobre a formação necessária a seus respectivos professores. Tais polêmicas de alguma forma eclipsaram os debates sobre a higiene, na medida em que esse parecia ser um terreno menos disputado, pois nele o campo médico constituía autoridade inconteste.

Segundo Melo (1996), o I Congresso Brasileiro de Eugenia, realizado em 1929, aprovou como proposição, entre outras coisas, a organização de escolas superiores de Educação Física para, convenientemente, preparar os professores indispensáveis à cultura física nacional. De certa forma, foi mesmo um período fértil para a Educação Física. Em setembro de 1933, aconteceu no Rio de Janeiro a Conferência Nacional de Proteção à Infância, em que foram discutidos os temas: Educação Física da criança, o que se entende por Educação Física e como realizá-la nas diversas idades; Recreios e jogos organizados para as crianças; seu papel na vida e na educação; organizações municipais e Colônia de férias. No mesmo ano, foi criada a Escola de Educação Física do Exército, em substituição ao Centro Militar de Educação Física. Atentamos que não se trata de selecionar cronologicamente os fatos, mas de acompanhar na narrativa as diversas ações no período, as mudanças, isso sem contar o movimento nos outros estados.

Muito da efervescência da Educação Física na época aconteceu por meio do VII Congresso Nacional de Educação, promovido pela Associação Brasileira de Educação e realizado no Rio de Janeiro, em 1935. Marinho (1945) refere que o congresso foi dedicado inteiramente aos problemas da Educação Física. Foram apresentados treze trabalhos e realizadas seis conferências sobre o tema. O grande número de sugestões e debates, durante o Congresso, levaram mais tarde à criação efetiva da Divisão de Educação Física do Ministério da Educação e Saúde, a Escola de Educação Física e Desportos da Universidade do Brasil e um grande número de escolas, cursos, diretorias e inspetorias especializadas disseminadas pelos estados. "Os educadores construíram um projeto cultural maior, no qual as prescrições para a Educação Física emergiam modificando sensibilidades e modos de ver e de prescrever uma educação do e para o corpo" (LINHALES, 2009, p. 77).

No ano de 1937, o Conselho Nacional de Educação encaminhou o Plano Nacional de Educação ao Ministério da Educação e Saúde. O plano previa a Educação Física obrigatória em todos os estabelecimentos de ensino primário, secundário, facultativo nos cursos superiores e uma Escola Superior de Educação Física destinada ao preparo profissional de instrutores e professores. Porém, o plano não chegou a ser enviado ao Presidente, nem ao Poder Legislativo; ou seja, ficou no desejo e na boa intenção, mesmo porque outras perspectivas cívico-nacionalistas estavam acima das 
pedagógicas. Parecia que a Educação Física continuava como um ponto fora da curva nas prioridades educacionais, mas, de certa forma, ocupando espaço no currículo escolar brasileiro.

A Educação Física nacional parecia viver um mundo à parte em relação ao que começava a se idealizar como Educação Nova no Brasil. É sabida a influência que Anísio Teixeira sofreu da educação americana. Isso fez-lhe perceber a necessidade de um maior tempo de permanência dos alunos na escola, a organização dos espaços destinados às atividades e a inclusão de disciplinas, como: música, educação física, educação de saúde, artes domésticas, dentre outras, no currículo escolar. Indicava, também, que a aprendizagem deveria estar relacionada com a formação de hábitos, pois defendia que só aprendemos quando assimilamos uma coisa de tal jeito que, chegado o momento oportuno, sabemos agir de acordo com o aprendido (NUNES, 2010; CAVALEIRE, 2010).

Observa-se que a Educação Física estava inserida no conjunto de precariedades da educação, mas também da escola, com a falta de espaço físico, de equipamentos e despreparo dos professores. Para Anísio, a velha escola tradicional não precisava de muitas justificativas para ser alterada profundamente; bastava observar a modificação social que o Brasil passava e o fato de a escola ser suplementar e preparatória, com informações e fatos de natureza livresca. Ele inferia que "A escola é uma replica da sociedade a que ella serve. A escola tradicional era a replica da sociedade velha que estamos vendo desapparecer. É facil desmontal-a e mostrar como todos os presuppostos em que ella se baseava foram alterados pela nova ordem de cousas e pelo novo espirito de nossa civilização" (TEIXEIRA, 1930 [on-line])

Dessa forma, o surgimento da Escola Nova era fruto de um descontentamento com a educação tradicional. Entretanto, a concepção anisiana não propunha romper com a escola tradicional por completo, mas defendia a conexão entre experiência e educação e a necessidade da experiência combinada com o ensino de matérias regulares. (FGV/CPDOC, 1931)

A reconstrução/reforma conduzida por Anísio se aproximava mais da Escola Progressiva do que da Escola Nova, talvez porque era fraca a correspondência entre seus princípios de um lado e uma prática de outro. Verifica-se que a escola, como recurso civilizatório, destacava algumas disciplinas do currículo para essa função, por exemplo: artes, higiene, desenho, música e educação física. Entre os diversos componentes curriculares, a Educação Física teve maior evidência nesse papel, porque atuava diretamente na adequação e modelação dos indivíduos, em seus comportamentos, na técnica e na conduta corporal. Dessa forma, no cotidiano da escola, a Educação Física estabeleceu relações mais próximas com artes, higiene, desenho e música, pois tais disciplinas passaram a ter um certo destaque e importância na educação do corpo do que outras (MOREL, 2016).

De todo jeito, essas reflexões não chegaram a invadir o ideário da área e a Educação Física continuou contemplada nesse projeto de regeneração do povo brasileiro. Passou a ser merecedora de 
grande destaque, visto que poderia coparticipar e, por assim dizer, transformar os nossos habitantes em um povo: viril, corajoso e, ao mesmo tempo, fiel, obediente, dócil, que, segundo o discurso ideológico dominante da época, era indispensável ao desenvolvimento da nação (BETTI, 1991; HORTA, 1994; CASTELLANI, 1988).

A Educação Física estruturou-se profissionalmente na luta pelo seu espaço na sociedade. Ganhou como principal reforço, no seu processo de legitimação e reconhecimento social de seus profissionais, a Constituição de 1937, que tornou a Educação Física obrigatória nas escolas, fazendo surgir outras demandas relacionadas à profissão, a exemplo da necessidade de se construir um currículo mínimo para a graduação em Educação Física (HORTA, 1994; CASTELLANI, 1988).

Nesse contexto, Getúlio Vargas (1937), citado por Castellani (1988, p. 84), relata a contribuição da Educação Física na ideologia nacionalista:

[...] não sendo uma simples fornecedora de noções técnicas, mas um instrumento de integração da infância e da juventude na Pátria, nos interesses sociais que lhes são incorporados, a educação da mocidade, nos preceitos básicos estabelecidos pelo novo Estado, será um elemento não só eficaz, como até decisivo na luta contra o comunismo e outras ideologias que pretendam contrariar e subverter o ideal de nacionalidade e as nossas inspirações cívicas, segundo as quais a juventude agora mais do que nunca, será formada [...].

Em outra direção caminhava a concepção de educação nova, certamente pragmática, objetivando servir não aos interesses de classes, mas aos interesses dos indivíduos. Fundando-se sobre o princípio da vinculação da escola com o meio social, tem o seu ideal condicionado pela vida social, mas profundamente humano, de solidariedade, de serviço social e cooperação. É certo que é preciso fazer indivíduos, pessoas, antes de fazer instrumentos de produção, assinalava o pensamento da Escola Nova.

Ora, se a educação está intimamente vinculada à filosofia de cada época, que lhe define o caráter, rasgando sempre novas perspectivas ao pensamento pedagógico, a educação nova não pode deixar de ser uma reação categórica, intencional e sistemática contra a velha estrutura do serviço educacional, artificial e verbalista, montada para uma concepção vencida (TEIXEIRA, 1984, p. 411).

A Educação Física estava destacada com um papel bastante singular, ligada desta forma a um projeto de segurança nacional, “[...] algo muito mais complexo do que simples preocupação com uma disciplina escolar" e isso acabou se refletindo direto na constituição estratégica desta como disciplina no currículo das escolas (MELO, 1996, p. 33).

Em 1939 é criado no Brasil o primeiro curso de Formação em Educação Física vinculado a uma Universidade. Grunenvaldt (1997) observa que, das 18 cadeiras que compunham o currículo da Escola Nacional de Educação Física e Desportos (ENEFD), para formar o professor de Educação Física, oito cadeiras organizavam seus conteúdos à luz dos conhecimentos das ciências biológicas; 
oito cadeiras dispunham sobre conteúdos sob a orientação do conhecimento técnico; e somente duas cadeiras - Metodologia do Ensino da Educação Física e do Treinamento Desportivo, História e Organização da Educação Física e dos Desportos - buscavam subsídios para a organização dos seus conteúdos nas ciências do homem e da sociedade.

Vejam que a principal referência para a educação e a escola na perspectiva anisiana não se fazia presente nessa modelagem de formação de professores e de constituição da área - a filosofia da educação. Ainda segundo Grunenvaldt (1997), o caráter de cientificidade presente nesse alvorecer da Educação Física nacional, provinha da biologia e da fisiologia, contemplando um paradigma organicista pautado numa abordagem positivista de ciência.

Em paralelo a essa construção da concepção da Educação Física nacional, o pensamento anisiano ancorava uma crítica contundente à educação pautada e reduzida a ler, escrever e contar. Indicava a necessidade de outros implementos no processo educativo. A mente, considerada uma faculdade puramente intelectual e cognitiva, era separada dos órgãos físicos. A atividade física, a atividade do corpo, acabou se tornando intrusa, como se não tivesse relação com o mental. Podemos observar essa crítica feita por Anísio, conforme citada no texto de Portugal et al. (2015):

Antes da escola, a criança aprende com as mãos, os olhos, os ouvidos, etc., porque mãos, olhos e ouvidos são órgãos do processo do fazer alguma coisa com sentido. $\mathrm{Na}$ escola, porém, o sentido é treinado isoladamente, sem conexão com um ato com objetivo, e isso é o que torna mecânico (PORTUGAL et al. 2015, p. 532).

A Educação Física era um dos elos do projeto de modernização a ser implantado por Anísio, cumprindo uma função educativa, regeneradora, moralizante do espaço social e escolar, com novas atitudes e comportamentos. No entanto, ela era mais conhecida na escola tradicional por resumir-se a aulas puramente formais de ginástica, sem orientação educativa, em espaços improvisados, sem organização adequada e professores despreparados. "A ação pedagógica de Anísio Teixeira nas escolas experimentais, nesse caso, voltar-se-á para a reformulação dos métodos de ensino, a redefinição do tempo e dos espaços escolares e a valorização dos princípios científicos, da Educação Física, do belo e da ideia de pátria" (CHAVES, 2006, p. 07).

Verificamos o segundo fato, no que diz respeito às ideias refletidas na inauguração do Centro Educacional Carneiro Ribeiro (CECR) em 1950, constituído de Escola-Classe e Escola Parque. Tal fato, nos parece evidente que, no projeto arquitetônico proposto por Anísio Teixeira, a constituição de espaços físicos específicos para as diversas práticas corporais, assim como a Educação Física, a recreação e os jogos, a música, as artes e o desenho, ajustavam o corpo para procedimentos de controle disciplinares, hábitos e condutas no ambiente escolar, por meio das rotinas de aprendizagem em conexão com o projeto civilizador e com uma escola viva e alegre. 
A valorização desses quesitos transformou sua proposta pedagógica e arquitetônica num movimento inovador, de vanguarda, mas, ao mesmo tempo, complexa para um sistema de educação que insistia em estruturas arcaicas. Sendo assim, necessitava de mais espaço, mais tempo, mais escolas, melhor formação de professores, mudança curricular, ou seja, no seu todo, uma alteração de atitudes e de concepções teóricas. No entanto, esbarrava em um Estado, Bahia, que só assistiu à concretização de seu primeiro curso de Formação em Educação Física em 1973.

\section{Educação Física na Bahia no nascimento da Escola Parque}

O Estado da Bahia exerceu forte influência na política educacional nacional. Personalidades como Rui Barbosa e Anísio Teixeira bem retratam esse percurso, além do pioneirismo na instalação de cursos superiores de Medicina e Direito. Todavia, a trajetória para a cristalização da formação em Educação Física foi por demais confusa e penosa. Antes da constituição do primeiro curso no Estado, professores foram estudar inicialmente na escola de Educação Física do Exército e posteriormente na ENEFD com o mecanismo de bolsas de estudos, ambas no Rio de Janeiro.

Com o retorno desses profissionais, especialmente da ENEFD, foram produzidas na Bahia iniciativas para a concretização de um curso superior de Educação Física. A primeira experiência aconteceu em 1942, sob inspiração do educador Isaias Alves, outra em 1965 no Governo de Lomanto Júnior, em 1969 com Luís Viana Filho e em 1973, presenciamos a criação e subsequente materialização do primeiro Curso Superior de Educação Física na Bahia (FERRARO, 1991).

Importante notar que todos esses movimentos se deram em épocas em que, em menor ou maior grau, o país vivia um contexto político no qual os ventos democráticos estavam reprimidos e, certamente, a perspectiva de formação pautada estava muito longe do entendimento da Educação

Física como uma disciplina pedagógica, que focasse o desenvolvimento crítico, percebendo o movimento como expressão de cultura, estando muito mais perto da doutrina da segurança nacional e do suposto desenvolvimento industrial.

Percebemos que o propósito de disseminar focos de Educação Física por todo o país, vislumbrado pelo Decreto lei n. ${ }^{\circ} 4.029$ de 1940, acabou impactando no processo tanto organizativo quanto metodológico das primeiras iniciativas em torno da criação do primeiro curso de Educação na Bahia e de experiências com o ensino da Educação Física como disciplina escolar.

Quando Anísio Teixeira retorna à administração pública no estado da Bahia, em 1947, parece inaugurar uma cena reconstruída de 25 anos antes, quando esteve à frente da Inspetoria Geral de Ensino da Secretaria do Interior, Justiça e Instrução Pública da Bahia. Mais uma vez, o educador 
trazia uma proposta de renovação para a escola primária. Para tanto, reconhecia que o Estado, a Igreja, a Família e a Escola eram instituições fundamentais, porém a mais dirigível, a mais deliberada e a mais intencional era a escola. Assim, era preciso dar ênfase e atuar diretamente nela. Em discurso pronunciado na inauguração do Centro Educacional Carneiro Ribeiro, Anísio Teixeira destaca:

É contra essa tendência à simplificação destrutiva que se levanta êste Centro Popular de Educação. Desejamos dar, de novo, à escola primária, o seu dia letivo completo. Desejamos dar-lhe os seus cinco anos de curso. E desejamos dar-lhe o seu programa completo de leitura, aritmética e escrita, e mais ciências físicas e sociais, e mais artes industriais, desenho, música, artes e educação física. Além disso, desejamos que a escola eduque, forme atitudes, cultive aspirações, prepare, realmente, a criança para a sua civilização - esta civilização tão difícil por ser uma civilização técnica e industrial e ainda mais difícil e complexa por estar em mutação permanente (TEIXEIRA, 1959, p. 79).

O CECR representava um projeto que refletia a concepção educativa anisiana para o funcionamento de uma escola primária adequada, de educação com qualidade, com cinco anos de duração, experimental, universal, democrática e com dia letivo completo. ${ }^{1}$ Era uma demonstração prática fundamentada na pesquisa educacional e social, na experimentação pedagógica e na descentralização administrativa.

O modelo de formação do magistério seria uma peça-chave nessa cadeia pedagógica e cívica. O novo professor deveria estar integrado e afinado com as práticas pedagógicas modernas, sobretudo na renovação dos métodos de ensino. Inserido de maneira relevante nessa estrutura, o corpo docente seria formado por professores comuns disponíveis às Escolas-Classe, professores especializados em artes industriais, biblioteca, música, educação física, recreação e jogos, dança, artes dramáticas e desenho, que atenderiam à Escola Parque com as suas diversas aptidões.

Dentro do terreno do Centro Regional de Pesquisa Educacional, funcionava a Escola de Aplicação, com horário integral para aproximadamente 150 crianças, que recebiam fardamento, alimentação e material didático. Nesse contexto, os centros regionais de pesquisa, as escolas experimentais e as escolas de aplicação tornaram-se lócus de treinamento e experimentação do magistério. Da mesma forma, Xavier (2007, p. 155) assinala que:

[...] articulavam-se no interior da escola, as atividades didáticas propriamente ditas, a observação e experimentação teórico-empírica, o debate intelectual e a permanente avaliação/reconstrução da prática docente, indicando que a capacitação do magistério deveria ser um processo contínuo e ininterrupto. Ainda, este processo de capacitação integrava-se com a própria atividade docente, reforçando a autonomia intelectual do professor ao mesmo tempo em que garantia, na própria organização interna da escola, os fatores imprescindíveis para sua efetivação, como tempo para a

\footnotetext{
${ }^{1} \mathrm{O}$ horário integral era sugerido das $7 \mathrm{~h} 30 \mathrm{~min}$ às $11 \mathrm{~h} 30 \mathrm{~min}$ e de $12 \mathrm{~h} 00 \mathrm{~min}$ às $16 \mathrm{~h} 30 \mathrm{~min}$.
} 
realização de estudos e espaço para a avaliação e a discussão teórica dos experimentos realizados na prática pedagógica.

A proposta de Anísio para os Centros de Treinamentos do magistério, enquanto concepção, seria valorosa, grandiosa e complexa, pois reconhecia a necessidade de preparo do professorado nacional em grande escala. Se aplicada como ele desejava, constituiria um avanço nunca antes alcançado, elevando em todos os níveis a profissão do professor, o que mudaria definitivamente o status da carreira do magistério, destravando uma tranca importante e deslanchando boa parte da educação brasileira. Contudo, era como superar o mais severo dos desafios; seria uma construção de décadas a fio, pois se tratava de um caminho longo, árduo, complicado e penoso (MOREL, 2016).

A ideia de pertencimento a uma instituição, Escola Parque, certamente criou identidades, significados e laços importantes com a comunidade escolar como um todo. Diversas ações e várias circunstâncias realçaram ainda mais um projeto tido como arrojado e pioneiro. Para Menezes (2000, p. 148), a Escola Parque mostrava o "outro lado da educação básica”. Assim, podemos afirmar que a Escola Parque se tornara uma escola-modelo planejada para educar de forma ampliada, valorizando a educação do corpo e com capacidade para se estabelecer como agente de mudança cultural, inclusive com projeção internacional. ${ }^{2}$

\section{A EDUCAÇÃO FÍSICA NA (COM) A ESCOLA PARQUE: Bahia dos anos 1950}

Anísio Teixeira estava propondo, com a implantação do Centro em setembro de 1950, uma verdadeira revolução. Recorremos a um trecho extraído de seu relatório administrativo de 1935, quando ainda este era Secretário de Educação no Rio de Janeiro: [...] só existirá uma democracia no Brasil no dia em que se montar, no Brasil, a máquina que prepara as democracias (TEIXEIRA, 1935 apud DOREA, 2000, p. 157).

Frente àquela conjuntura, Nunes (2009, p. 123) apresenta uma síntese do que Anísio defendia ser o papel do sistema de ensino a ser implantada na Bahia: "tratava-se, portanto, de expandir, do ponto de vista da cultura geral, a instrução primária [...], para que a população, sobretudo das áreas mais pobres, se integrasse no contexto de uma sociedade moderna”. Cuja finalidade seria: “a) (...) preparar o homem para indagar e resolver por si os seus problemas”, e ainda: "b) (...) construir a nossa escola, não como preparação para um futuro conhecido, mas para um futuro rigorosamente imprevisível” (TEIXEIRA, 1930, p. [2?]).

O pensamento anisiano apresentava uma educação e uma escola que se distinguia do

${ }^{2}$ O CECR era tido como modelo educacional para a UNESCO. Segundo Viana Filho (1990, p. 125) “Anísio informou aos seus ouvintes: As Nações Unidas, em um documentário de escolas de todo mundo, escolheram este Centro para um dos seus filmes e o exibiram em toda parte". 
pensamento hegemônico e do valor educacional vigente (CAVALIERE, 2010). Na sua fala inaugural, Anísio enfatizava a transformação da comunidade e a construção de uma autonomia, tendo como base os fundamentos da vida democrática numa sociedade em miniatura, que estaria na integração da Escola-Classe com a Escola Parque.

A escola primária terá, em seu conjunto, algo que lembra uma pequenina universidade infantil. Mas, de nada menos, repito, precisamos em nossa época, para ficarmos à altura das imposições que o progresso técnico e científico nos está a impor. Queiramos, ou não queiramos, vamo-nos transformar de uma sociedade primitiva em uma sociedade moderna e técnica. Os habitantes dêste bairro da Liberdade deixam um estágio anterior aos tempos bíblicos de agricultura e vida primitiva para imergirem em pleno báratro do século vinte. Ou organizamos para êles instituições capazes de lhe preparar os filhos para o nosso tempo, ou a sua intrusão na ordem atual terá o caráter das intrusões geológicas que subvertem e desagregam a ordem existente (TEIXEIRA, 1959, p. 84).

Verifica-se que os espaços de aprendizagem iam muito além da escola; a expansão e ampliação do conhecimento e do progresso eram a possibilidade de uma vida melhor, da promoção social via escola, da possibilidade do indivíduo ser educado para viver numa sociedade democrática e participar ativamente dela. Seria a "reapropriação de espaços de sociabilidade crescentemente sonegados às classes trabalhadoras pelas reformas urbanas que lhes empurravam para a periferia da cidade" (NUNES, 2010, p. 32).

A proposta do Centro materializou um ideal de escola de tempo integral que ampliava não só o tempo dos estudantes na escola, "dia letivo cheio", mas também ampliava o acesso ao conhecimento que não deveria se reduzir à alfabetização. O educador indicava que era contra essa tendência à simplificação destrutiva e foi no sentido de diferir que se levantava esse centro popular de educação. O desejo girava em torno de dar seu programa completo de leitura, aritmética, escrita, ciências físicas e sociais, artes industriais, desenho, música, dança e educação física (CAVALIERE, 2010; TEIXEIRA, 1959).

Cabe então refletir sobre o papel da Educação Física nesse projeto. É certo que, no plano mais geral, o pensamento anisiano contrapunha-se ao autoritarismo que havia imperado no Estado Novo. Teria ele uma concepção de Educação Física integrada ao projeto de homem, educação e do programa do Centro, diferente daquele de viés autoritário forjado nos meandros da influência militar na área, que combatia toda e qualquer forma de expressão de divergência a esse modelo (HORTA, 1994). Assim, podemos constatar, e atribuir ao pensamento de Anísio Teixeira, a noção de educação integral com a finalidade de reconstrução das bases sociais para o desenvolvimento democrático (CAVALIERE, 2010, EBOLI, 1969; NUNES, 2009; 2010). 
$\mathrm{Na}$ perspectiva anisiana, existia uma conjuntura pedagógica, curricular, arquitetônica, espacial, de tempos e horários que viabilizavam uma educação voltada para o corpo. Assim, a educação básica seria estruturada no currículo formal com conteúdos para interpretar o mundo e, em parte, com conteúdos para o fazer, implicado numa educação por meio da educação física, recreação, jogos, artes, música, higiene, desenho e da potencialização de habilidades manuais, com aulas e atividades - como, por exemplo, marcenaria, corte e costura, confeitaria, cerâmica, artesanato e outros ofícios de cunho profissionalizante. De tal modo, Eboli (1969) descreve o ambiente da Escola Parque:

Não há formalismo, não há rigidez na disciplina. Em poucos minutos, aquela onda humana é absorvida pelos setores onde inicia suas atividades. Os ruídos das serras elétricas, das máquinas de costura, os martelos batendo solas, metal ou madeira, no setor de trabalho; a melodia do piano, da banda de música, do canto coral que se eleva do setor artístico; os apitos de jogos, a marcação sistemática de ginástica no setor recreativo (p. 35).

Nesse sentido, Anísio avançava para a compreensão que rejeitava a divisão da realidade em dois planos, um psíquico e outro material. Ao contrário disto, ao defender uma formação ampliada e a articulação entre atividades de instrução e de socialização, nos dava indícios de que, no seu modo de pensar, havia apenas uma realidade. Portanto, um conhecimento a ser construído, aquele fruto da experiência humana.

$\mathrm{Na}$ formulação do modelo pedagógico para organização e funcionamento do Centro, consideramos ter sido a noção de corpo, de educação física e de jogos de John Dewey referência para o lugar da Educação Física na/com a escola, na estrutura do programa de atividades da Escola Parque. Assumindo essa referência, é possível que haja diferenças significativas nos objetivos da Educação Física no Centro, quando comparado ao papel e às finalidades da Educação Física nas escolas que seguiam o preconizado pelo pensamento da área, de um modo mais geral, no Brasil e na Bahia com primazia da influência das instituições médicas e militares, certamente, porque bebiam de influências europeias (BETTI, 1991; CASTELANI, 1988; HORTA, 1994; MELO, 1996).

Para Betti (1991) há nas contribuições das ideias de John Dewey na Educação Física a construção de um novo discurso sobre a área, um entendimento da Educação Física como meio da Educação, como fator de desenvolvimento integral de crianças e jovens. Entretanto, esse autor alerta para o fato dessa concepção ter alterado mais os discursos do que as práticas, que continuavam fortemente assentadas no higienismo e no militarismo. 
Sob o enfoque influenciado por Dewey, por princípio, os olhares no Centro estavam mais voltados para formar crianças e jovens para uma sociedade em mudanças e para o exercício de sua cidadania, em detrimento de um projeto voltado para a docilização de corpos e de afirmação de uma identidade nacionalista. Segundo Anísio, “[...] a escola treinava o corpo de forma mecânica e instrumental, sem considerar que deveria educar os sentidos de forma ampla, considerando a condição corporal de viver" (apud PORTUGAL et al., 2015, p. 532).

A esse respeito, Portugal et al. (2015) trazem em seu estudo um trecho extraído do relatório feito por Anísio “[...] a experiência norte-americana mostrou para o educador que o corpo do aluno era negado pela escola brasileira". E complementa "Valha-nos que, hoje, um certo enriquecimento dos programas com educação física e esportes está a oferecer condições que ainda são sensivelmente medíocres" (TEIXEIRA, 2006 apud PORTUGAL et al. 2015, p. 533).

Os registros encontrados sobre a Educação Física e Recreação no CECR revelam o entendimento que sustentava a presença dessa disciplina no projeto integrado à Escola Parque. Eboli (1969) apresenta um fragmento do que seria o registro no diário de uma estagiária das aulas observadas de Educação Física na Escola Parque, em uma turma de meninas:

Iniciam a aula com uma atividade viva, alegre; uma roda, um brinquedo cantado, ou um pequeno jogo com bola. As meninas estão alegres, seus rostinhos mostram bem como ficam felizes com a recreação. Depois da primeira fase da aula, do jogo simples, as meninas fazem a mando do professor a "formação corporal", que pode ser exercício (ginástica) e ele vai corrigindo a posição de uma ou de outra. Algumas têm defeito de postura que o professor, com paciência, vai tentando corrigir. O final da aula é feito com um jogo calmo e ao terminar, juntam-se todas as meninas ao redor do professor para ouvir o que ele tem a falar [...]. Ficam atentas ouvindo o comentário da aula (p. 27).

A descrição acima marca indícios de uma preocupação do educador e das práticas ali desenvolvidas com uma educação de corpo inteiro, na acepção de conceber mente e corpo de forma indissociável. À vista disso, relacionando esse pensamento ao conceito de Reconstrução da Experiência, inferimos que na perspectiva desse educador a vida humana é um processo de educação, de formação e de aquisição de experiências em que os sentidos e a corporeidade possuem um valor central.

Em outra passagem, Eboli (1969, p. 20) descreve suas percepções sobre as atividades de Educação Física no “[...] setor de Educação Física e Recreação: jogos, recreação, ginástica etc.”, a nosso ver, incorporando essa atividade aos códigos e função da Escola Parque com o Centro:

No pavilhão, ou nas áreas ao ar livre, a infância fervilha em movimento: marchas, galopes, saltos, arremessos, jogos de bola, ginástica, calistenia, aparelho em movimento, basquete, futebol etc. Tudo funcionando como um grande ginásio esportivo [...] É onde a alegria da criança se faz notar com maior intensidade (EBOLI, 1969, p. 55). 
A destinação de horários para toda essa multiplicidade de atividades educativas também incidia sobre o corpo, já que eram reguladas pelo tempo; porém, sem os atropelos do tempo do relógio guiado por segundos, minutos, horas e da forma acelerada do mundo externo, mas, o tempo internalizado automaticamente por uma sistemática de revezamento de locais, professores e atividades voltadas para uma rotina escolar ampliada. Desse modo, absorvia-se uma demanda costumeira e disciplinar, que, aos poucos, ia satisfazendo o cumprimento de horários para os deslocamentos e o desenvolvimento de atividades individuais e coletivas, mas, principalmente, de forma cooperativa e colaborativa em espaços comuns. Ao expressar suas percepções sobre o cotidiano das aulas de Educação Física e Recreação, Eboli (1969) apresenta o que seriam os objetivos dessas atividades no projeto do setor:

Objetivos gerais das atividades recreativas: saúde da criança, aproveitamento condigno das horas de lazer; formação do caráter e afirmação da personalidade; preparação pré-vocacional dos maiores para o campo dos esportes (p. 55).

Em tempo que os objetivos para as aulas de Educação Física, acima descritos como sendo aqueles que orientariam o trabalho no Centro, no contexto da Escola Parque, podemos considerar certa ampliação nas finalidades, na metodologia e nos conteúdos a serem ensinados nas aulas de Educação Física e Recreação. A presença dos jogos, de brincadeiras e do lazer, de uma dinâmica de aula que considera (no início e no fim da aula) a prática de reunir-se em círculo (em que o professor tratava com os estudantes e/ou comentava com estes sobre a aula), merece uma reflexão e maior investigação, uma vez que essas ações não coadunavam com o modelo instrucional baseado nos modelos militares, os quais orientavam as práticas de ensino na área.

Eboli (1969, p. 55), apresenta uma descrição dos conteúdos/atividades desenvolvidas com as crianças e jovens, organizadas por grupos etários e por sexo:

[...] são organizadas em planos mensais, pela coordenação técnica, e abrangem as seguintes áreas: a) atitudes naturais - correr, saltar, trepar, arremessar etc; b) jogos - motores, sensoriais etc. adaptados às condições físicas e psíquicas das crianças; c) atividades rítmicas - marchas, galopes, saltitos, ao som de ritmos, palmas, contagem, tamborim; brinquedos cantados, danças regionais e folclóricas; d) atividades ginásticas - jogos ginásticos, exercícios ginásticos (método francês), calistenia, método sueco, desportiva generalizada, método austríaco, ginástica feminina moderna, ginástica de solo, e em aparelhos; e) iniciação desportiva, com princípios técnicos essenciais, processos pedagógicos, jogos pré-esportivos ou grandes jogos; f) desportos, basquete, voleibol e futebol. Há, ainda, na programação, as atividades chamadas complementares que são as excursões, concentrações, demonstrações, competições. 
Se as representações, excertos e o relato feito por Eboli (1969) traduzirem a natureza do trabalho pedagógico no Centro de forma fidedigna, temos evidências e indícios da possibilidade de que, na Escola Parque, as atividades de Educação Física mantinham relações mais gerais com a construção de representações e o pensamento da área no período. Contudo, também assumiu códigos e funções específicas do projeto da escola e de sua cultura de ensino, com base no pensamento anisiano. Cabe, pois, identificar entre os conteúdos/atividades presentes no programa de educação física da Escola Parque temas como aqueles descritos nas letras "c" / "e", sem deixar de considerar os demais aspectos colocados em relevo: descrição do contexto das aulas; metodologia de ensino que privilegiava as rodas de início e fim de aula, um conjunto de jogos espontâneos, bem como de relações entre as atividades do setor e dos demais setores que integram o CERC.

Observamos serem esses indicativos de atitudes corporais adequados no projeto anisiano, pelo fato de incentivarem a livre circulação pelo ambiente, pelo exercício da autonomia e da independência no processo ativo que, igualmente, estimulava o autocontrole em outras pessoas e coisas, em função do corpo que existe, ocupa e se movimenta nesse espaço propício.

Procurando reorganizar o tipo de estratificação educacional e social que condenava, por limitar e confinar o corpo na escola, a concepção educativa anisiana acabava por incutir, de forma sutil, representações culturais e morais construídas simbolicamente através do canto, da dança, dos jogos e das artes. "Essas práticas tomaram conta dos pátios escolares, dos teatros, das ruas e dos estádios esportivos de forma a reunir, através de movimentos formalizados, a educação individual e social e a reelaborar a cultura popular" (NUNES, 2000, p. 370). Revisitar a Escola Parque nos insta a refletir, a querer conhecer e investigar mais esse contexto. Incentiva ainda conhecer a experiência desse Centro e da Educação Física, que demonstrava que ser possível se diferenciar no cenário educacional, todavia, mesmo frente ao paradoxo dessa e de outras experiências serem ofuscadas nos sistemas de educação no Brasil.

\section{CONSIDERAÇÕES FINAIS}

O pensamento anisiano concebia uma educação e escola com finalidades formativas ampliadas, no poder transformador destas, para uma sociedade em movimento, moderna e democrática. Os desejos de renovação no projeto anisiano estiveram voltados para uma nova competência escolar, influenciada pela pedagogia escolanovista em detrimento da pedagogia tradicional. Para se tornar realidade, foram necessárias mudanças no espaço físico e na arquitetura escolar, maior interação entre o currículo e o processo de ensino-aprendizagem, incremento da 
capacitação e formação de docentes, aquisição de equipamentos e um sistema administrativo que desse conta de dinamizar tudo isso.

A nosso ver, a expressividade, as manifestações físicas e artísticas trabalharam por duas frentes distintas e tinham efeitos opostos: por um lado, proporcionavam a liberdade corporal, artística e estética, por outro, disciplinavam corpos, condutas e sentimentos. Entretanto, todos os efeitos somados eram relevantes para uma educação do corpo. Essa tessitura social estava em construção e se encontrava altamente capilarizada desde a década de 1930, auxiliando na edificação do projeto civilizatório, sempre regulado e cheio de tensões.

Anísio Teixeira formulava a ideia de uma escola de tempo integral e de educação integral, tendo como base a concepção de que as pessoas se desenvolvem na ação, ao (re)construir experiências. Uma educação cuja base não se sustentava em dicotomias, como escola para brancos ricos e pretos pobres, corpo e mente. Tampouco de hierarquização entre trabalho intelectual e manual, até porque, sobre esse último aspecto, o trabalho corporal na sua perspectiva era também intelectual e vice versa.

O Centro Educacional Carneiro Ribeiro se materializou como um projeto para a educação popular no estado da Bahia, cujo um pouco das suas finalidades e características buscamos anteriormente retratar. Integrado a um programa de atividades educativas e de socialização ofertados na Escola Parque, uma proposta de Educação Física Escolar foi produzida, tomando como epicentro os códigos e valores desse Centro, de base filosófica e pedagógica do pensamento anisiano.

Essas incursões sobre o pensamento de Anísio Teixeira e a Educação Física são apenas uma aproximação inicial. Mais que constatações categóricas, os achados iniciais e as hipóteses levantadas nos convidam a realizar novas pesquisas, a aprofundar análises teóricas e a buscar evidências empíricas que possam sustentar a defesa de uma Educação Física pensada nos anos de 1950 que, apesar de desejada na época por alguns intelectuais, só veio a ser anunciada e materializada no âmbito do processo de redemocratização do Brasil no início dos anos 1980.

No Centro Educacional Carneiro Ribeiro, verificamos que a educação do corpo era protagonista nas atividades escolares, integrando a Escola-Classe com a Escola Parque, evidenciando a ampliação do tempo com o alargamento das experiências educativas, dinamizando, assim, o currículo, o espaço e o tempo escolar. Destarte, faz-se necessário aprofundar estudos, como também realizar outros, relacionados aos registros e às memórias daqueles que participaram dessa história, com o protagonismo para os professores, funcionários e seus estudantes. 


\section{REFERÊNCIAS}

AGUIAR, André Andrade de. Avaliação da microbiota bucal em pacientes sob uso crônico de penicilina e benzatina. 2009. Tese (Doutorado em Cardiologia) - Faculdade de Medicina, Universidade de São Paulo, São Paulo, 2009.

BAUMAN, Zygmunt. Globalização: as consequências humanas. Rio de Janeiro: Jorge Zahar, 1999.

BAVARESCO, Agemir; BARBOSA, Evandro; ETCHEVERRY, Katia Martin (orgs.). Projetos de filosofia. Porto Alegre: EDIPUCRS, 2011. E-book. Disponível em:

http://ebooks.pucrs.br/edipucrs/projetosdefilosofia.pdf. Acesso em: 21 ago. 2011.

BRASIL. Lei nº 10.406, de 10 de janeiro de 2002. Institui o Código Civil. Diário Oficial da União: seção 1, Brasília, DF, ano 139, n. 8, p. 1-74, 11 jan. 2002. PL 634/1975.

BRASIL. Ministério da Fazenda. Secretaria de Acompanhamento Econômico. Parecer técnico no 06370/2006/RJ. Rio de Janeiro: Ministério da Fazenda, 13 set. 2006. Disponível em: http://www.cade.gov.br/Plenario/Sessao_386/Pareceres/ParecerSeae-AC-2006-08012.008423International_BusInes_MachIne. PDF. Acesso em: 4 out. 2010.

FERREIRA, Léslie Piccolotto (org.). O fonoaudiólogo e a escola, 2 ed. São Paulo: Summus, 1991.

FUNDAÇÃO BIBLIOTECA NACIONAL (Brasil). BNDIGITAL I: Coleção Casa dos Contos. Rio de Janeiro, 23 fev. 2015. Facebook: bibliotecanacional.br. Disponível em: https://www.facebook.com/bibliotecanacional.br/photos/a.241986499162080.73699.217561081604622/1023 276264366429/?type=1\&theater. Acesso em: 26 fev. 2015.

VOLPATO, Gilson Luiz. Como escrever um artigo científica. Anais da Academia Pernambucana de Ciência Agronômica, v. 4, p.97-115, 2007. Disponível em: http://www.gilsonvolpato.com.br/pdf/2007\%20Volpato\%20$\% 20$ Como\%20escrever\%20um\%20artigo\%20cient_fico\%20-\%20Academia\%20Pernambucana.pdf. Acesso em: 24 nov. 2018.

IBGE. Amparo: região sudeste do Brasil. 2. ed. Rio de Janeiro: IBGE, 1983.

LUCK, Heloisa. Liderança em gestão escolar. 4. ed. Petrópolis: Vozes, 2010.

POLÍTICA. In: DICIONÁRIO da língua portuguesa. Lisboa: Priberam Informática, 2013. Disponível em: http://www.priberam.pt/dlDLPO. Acesso em: 8 mar. 2016.

ROMANO, Giovanni. Imagens da juventude na era moderna. In: LEVI, Giovani; SCHMIDT, Jean-Claude. (orgs.). História dos jovens 2: a época contemporânea. São Paulo: Companhia das Letras, 1996. p. 7-16.

TAVARES, Raul. O combate naval do Monte Santiago. Revista do Instituto Histórico e Geográfico Brasileiro, Rio de Janeiro, v. 155, t. 101, p. 168-203, 1953.

\section{NOTAS DE AUTOR}

FINANCIAMENTO - Não se aplica.

APROVAÇÃO DE COMITÊ DE ÉTICA EM PESQUISA - Não se aplica.

CONFLITO DE INTERESSES - Os autores declaram não haver conflito de interesses. 


\section{LICENÇA DE USO}

Os autores cedem à Motrivivência - ISSN 2175-8042 os direitos exclusivos de primeira publicação, com o trabalho simultaneamente licenciado sob a Licença Creative Commons Attribution NonComercial ShareAlike (CC BY-NC SA) 4.0 International. Esta licença permite que terceiros remixem, adaptem e criem a partir do trabalho publicado, desde que para fins não comerciais, atribuindo o devido crédito de autoria e publicação inicial neste periódico desde que adotem a mesma licença, compartilhar igual. Os autores têm autorização para assumir contratos adicionais separadamente, para distribuição não exclusiva da versão do trabalho publicada neste periódico (ex.: publicar em repositório institucional, em site pessoal, publicar uma tradução, ou como capítulo de livro), com reconhecimento de autoria e publicação inicial neste periódico, desde que para fins não comerciais e compartilhar com a mesma licença.

\section{PUBLISHER}

Universidade Federal de Santa Catarina. Programa de Pós-Graduação em Educação Física. LaboMídia - Laboratório e Observatório da Mídia Esportiva. Publicado no Portal de Periódicos UFSC. As ideias expressadas neste artigo são de responsabilidade de seus autores, não representando, necessariamente, a opinião dos editores ou da universidade.

\section{EDITORES}

Mauricio Roberto da Silva, Giovani De Lorenzi Pires, Rogério Santos Pereira.

\section{EDITOR DE SEÇÃO}

Giovani De Lorenzi Pires

\section{REVISÃO DO MANUSCRITO E METADADOS}

João Caetano Prates Rocha; Keli Barreto Santos, Juliana Rosário.

\section{HISTÓRICO}

Recebido em: 05 setembro 2021

Aprovado em: 16 novembro 2021 